\title{
EFEKTIFITAS TEPID SPONGE BATH TERHADAP PENURUNAN SUHU TUBUH PADA ANAK KEJANG DEMAM DI RSUD LAWANG MALANG
}

\author{
Kasiati $^{1}$, Hurun Ain ${ }^{2}$, Nurul Hidayah $^{3}$, Faiqotul $^{4}$ \\ 1, 2,3,4 Prodi Keperawatan, Politeknik Kesehatan Kemenkes Malang
}

\begin{abstract}
A convulsion is a complaint that often makes a child come to the Accident and Emergency Department. Most febrile convulsion occurs due to fever. The treatment by nurses at the during of fever is to provide anti-pyretic's drug according to the physician's instructions and there is no non-pharmacological action in terms of lowering body temperature such as giving a warm compress (Tepid Sponge Bath). The purpose of this study is to know the effectiveness of Tepid Sponge Bath to decrease body temperature in children's febrile convulsion in the Adenium's room at RSUD Lawang. Design of the research used Quasi Experimental with the design type of Non-equivalent Control Group Design. The number of samples obtained as many as 26 respondents. The sample used Accidental Sampling Method. Measuring instrument for measuring body temperature in treatment group and control group used Digital Thermometer for forehead with 98\% accuracy level. The result of statistical analysis of Independent Sample t-test showed no difference of body temperature at minute 30.60 and 90 after TSB, but at minute 45 and 120 there was significant difference ( $p$ value $=0,000<0,05)$. The recommendation of this study is children who have fever to get Tepid Sponge Bath action because it can reduce the risk of febrile convulsion.
\end{abstract}

Keywords: Tepid sponge Bath, Children's body Temperature, Febrile Convulsions.

\section{A. PENDAHULUAN}

Kejang merupakan keluhan yang sering membuat anak datang ke UGD, sekitar 4 - 10\% anak setidaknya mengalami satu kali kejang selama masa kanak - kanak. Sebagian besar kejang sewaktu masa anak - anak merupakan kejang demam (Lalani, 2011).

Kejang demam dapat berjalan singkat dan tidak berbahaya, tapi bila kejang demam mencapai 15 menit dapat membahayakan pasien anak karena bisa menyebabkan kerusakan otak sehingga menyebabkan epilepsi, kelumpuhan, retardasi mental, kerusakan otak dan penurunan kesadaran (Dewanto, 2009). Dalam keadaan kenaikan suhu tubuh sebesar $1^{\circ} \mathrm{C}$ pun bisa menyebabkan kenaikan metabolisme basal (jumlah minimal energi yang dibutuhkan untuk mempertahankan fungsi vital tubuh) sebanyak 10-15\%, sementara kebutuhan oksigen pada otak naik sebesar 20\%. Pada anak balita aliran darah ke otak mencapai $65 \%$ dari aliran seluruh tubuh (pada orang dewasa hanya $15 \%$ ) sebab itu kenaikan suhu tubuh lebih mudah menimbulkan gangguan pada metabolisme otak sehingga akan mengganggu keseimbangan sel otak yang menimbulkan terjadinya muatan listrik yang menyebar keseluruh jaringan otak akibatnya terjadi kekauan otot yang menyebabkan kejang tadi (Walley dan Wong, 1996 dalam Koesrini, 2015).

Kompres adalah salah satu metode fisik untuk menurunkan suhu tubuh bila anak mengalami demam. Selama ini kompres dingin atau es menjadi kebiasaan yang 
diterapkan para ibu saat anaknya demam. Metode kompres yang lebih baik adalah kompres tepid sponge (Kolcaba, 2007:312) dalam penelitian Maling (2012:2).

Kompres Tepid Sponge adalah sebuah teknik kompres hangat yang menggabungkan teknik kompres blok pada pembuluh darah supervisial dengan teknik seka (Corrard, 2001:253) dalam Maling (2012:2). Pada saat pemberian Tepid sponging otak akan menyangka bahwa suhu diluar tubuh panas, sehingga otak akan segera memproduksi dingin dan terjadilah penurunan suhu tubuh. Dengan kompres hangat pada daerah yang mempunyai vaskular yang banyak, maka akan memperluas daerah yang mengalami vasodilatasi. Vasodilatasi yang kuat pada kulit, akan memungkinkan percepatan perpindahan panas dari tubuh ke kulit, hingga delapan kali lipat lebih banyak (Anas, 2006 dalam Melasi, 2013:3).

Tepid sponge bath dengan air hangat merupakan tindakan pendinginan yang masih sering diperdebatkan. Totapally (2005) menjelaskan bahwa tepid sponge bath dengan air hangat jika dilakukan dengan benar akan sangat efektif menurunkan demam dengan cepat. Akan tetapi, efek tepid sponge bath dengan air hangat selain menurunkan suhu tubuh, juga menyebabkan vasokontriksi pada awal prosedur. Vasokontriksi ini menyebabkan anak merasa kedinginan bahkan sampai menggigil, terutama jika tidak dikombinasikan dengan antipiretik.

Penelitian Thomas, et al, (2009). di India menunjukkan bahwa "pemberian antipiretik yang disertai tindakan tepid sponge dengan air hangat dapat menurunkan suhu lebih cepat dibandingkan dengan pemberian antipiretik saja". Menurut penelitian Setiawati (2008) "rata-rata penurunan suhu tubuh pada anak hipertermia yang mendapatkan terapi antipiretik ditambah tepid sponge sebesar $0.53{ }^{\circ} \mathrm{C}$ dalam waktu 30 menit, sedangkan yang mendapat terapi tepid sponge saja rata-rata penurunan suhu tubuhnya sebesar $0,97^{\circ} \mathrm{C}$ dalam waktu 60 menit". Menurut penelitian Melasi (2013) "terdapat kecenderungan bahwa pemberian antipiretik yang disertai tepid sponge bath mengalami penurunan suhu tubuh yang lebih besar dibandingkan dengan pemberian antipiretik saja".

Angka kejadian kejang demam di Amerika serikat dan di Eropa Barat pada tahun 2007 berkisar antara 8\% - 49\% (Brough, 2008). Di Indonesia dilaporkan penderitanya lebih tinggi sekitar 20\%, Berulangnya kejang demam lebih sering bila serangan pertama terjadi pada bayi berumur kurang dari 1 tahun yaitu sebanyak 50\%, bila kejang pertama terjadi pada usia lebih dari 1 tahun resiko berulangnya kejang adalah 28\%. (Buku Ajar Neurologi Anak, 2000:248) dalam Koesrini (2015).

Berdasarkan studi pendahuluan yang peneliti lakukan pada tanggal 10 November 2016 di Instalasi Rawat Darurat (IRD) dan Instalasi Rawat Inap Anak (IRNA) R. Adenium RSUD Lawang, Terdapat rata-rata 16 anak setiap bulan yang menderita kejang demam atau sekitar 2,5\% dari keseluruhan pasien, rata - rata pasien yang datang sejumlah 669 pasien setiap bulan dalam kurun waktu 6 bulan terakhir. Hasil wawancara didapatkan dari 2 orang perawat yang mewakili ruangan. Penanganan pertama yang dilakukan di IRD untuk mengatasi kejang demam yaitu dengan menggunakan medikamentosa untuk mengurangi gejala, tidak ada tindakan keperawatan yang dilakukan karena biasanya gejala sudah hilang dengan pemberian medikamentosa. Penanganan diruangan, karena biasanya kejang sudah tidak muncul, di ruangan hanya menurunkan demamnya saja, demam diturunkan dengan pemberian antipiretik sesuai advis dokter, tapi jika terjadi kejang brulang akan dilakukan pemberian obat antikejang diazepam rektal (stesolid) sesuai advis dokter, tidak ada tindakan non farmakologis 
dalam hal asuhan keperawatan yang dilakukan. Dan penelitian ini bertujuan untuk Mengetahui efektifitas tepid sponge bath terhadap penurunan suhu tubuh anak yang mengalami kejang demam di Ruang Adeniu RSUD Lawang

\section{B. TINJAUAN PUSTAKA}

Kejang demam merupakan bangkitan kejang yang terjadi pada kenaikan suhu tubuh (suhu rektal di atas $38^{\circ} \mathrm{C}$ ) yang disebabkan oleh suatu proses ekstrakranium. Kejang demam terjadi pada 2-4\% anak berumur 6 bulan -5 tahun. Anak yang pernah mengalami kejang tanpa demam, kemudian kejang demam kembali tidak termasuk dalam kejang demam.Kejang disertai demam pada bayi berumur kurang dari 1 bulan tidak termasuk dalam kejang demam. Bila anak berumur kurang dari 6 bulan atau lebih dari 5 tahun mengalami kejang didahului demam, pikirkan kemungkinan lain misalnya infeksi SSP, atau epilepsi yang kebetulan terjadi bersama demam (UKK IDAI, 2006)

Penyebab kejang demam masih belum dapat dipastikan.Sebagian besar anak, tingginya suhu tubuh tetapi bukan pada kecepatan kenaikan suhu tubuh yang menjadi faktor pencetus serangan kejang demam.Pada keadaan suhu demam melebihi $38,8^{\circ} \mathrm{C}$ dan terjadi saat suhu tubuh naik bukan pada saat setelah terjadinya kenaikan suhu yang lama. (Sodikin, 2012).

Biasanya kejang demam berlangsung singkat dan pada waktu pasien datang kejang sudah berhenti.Apabila datang dalam keadaan kejang obat yang paling cepat untuk menghentikan kejang adalah diazepam yang diberikan secara intravena.

Adapun tindakan Umum Penurunan Suhu secara Simtomatik adalah dengan mengusahakan agar anak tidur atau istirahat agar metabolismenya menurun. Cukupi cairan agar kadar elektrolit tidak meningkat saat evaporasi terjadi. Aliran udara yang baik misalnya dengan kipas, memaksa tubuh berkeringat, mengalirkan hawa panas ke tempat lain sehingga demam turun. Jangan menggunakan aliran yang terlalu kuat, karena suhu kulit dapat turun mendadak.Ventilasi / regulasi aliran udara penting di daerah tropik.Buka pakaian/selimut yang tebal agar terjadi radiasi dan evaporasi. Lebarkan pembuluh darah perifer dengan cara menyeka kulit dengan air hangat (tepidsponging). Mendinginkan dengan air es atau alkohol kurang bermanfaat (justru terjadi vasokonstriksi pembuluh darah), sehingga panas sulit disalurkan baik lewat mekanisme evaporasi maupun radiasi.Pada hipertermi, pendinginan permukaan kulit (surfacecooling) dapat membantu. Tindakan simtomatik yang lain ialah dengan pemberian obat demam. Cara kerja obat demam adalah dengan menurunkan set-point di otak dan membuat pembuluh darah kulit melebar sehingga pengeluaran panas ditingkatkan.Obat yang sederhana adalah asam salisilat dan derivatnya.Rentang daya kerja obat ini cukup panjang, aman untuk dikonsumsi umum. Beberapa golongan antipiretik murni, dapat menurunkan suhu bila anak demam namun tidak menyebabkan hipotermi bila tidak ada demam, seperti: asetaminofen, asetosal, ibuprofen. Obat lain adalah obat yang bersifat antipiretik pada dosis rendah dan menimbulkan hipotermi pada dosis tinggi seperti metamizol dan obat yang dapat menekan pusat suhu secara langsung (chlorpromazine), mengurangi menggigil namun dapat menyebabkan hipotermi dan hipotensi (Ismoedijanto. 2000). 


\section{METODE PENELITIAN}

Desain dalam penelitian ini adalah Quasi Experimental dengan jenis rancangan Nonequivalent Control Group Design. Teknik sampling yang gunakan oleh peneliti dalam penelitian ini adalah teknik non probability sampling dengan cara pengambilan sampel secara accidental yang dilakukan dengan mengambil kasus atau subyek penelitian yang kebetulan ada atau tersedia disuatu tempat sesuai dengan konteks penelitian. Instrumen yang digunakan adalah Thermometer dahi digital dan air hangat $29,4^{\circ} \mathrm{C}$ sampai $32,2^{\circ} \mathrm{C}$. Penelitian dilakukan di Ruang Adenium RSUD Lawang dilakukan selama 2 bulan pada periode tanggal 13 April -13 Juni 2017. Sampel yang digunakan sejumlah 36 responden.

Analisa data yang digunakan pada penelitian ini meliputi analisa univariat dan bivariat. Analisa univariat pada penelitian ini digunakan untuk menganalisis tingkat umur dan jenis penyakit penyerta dalam bentuk diagram batang. Analisa bivariat penelitian menggunakan analisa software SPSS 23.0 for windows dengan menggunakan uji Normalitas Shapiro wilk yang dilakukan sebelum analisis parametrik pada data yang berskala ratio yaitu suhu tubuh, Independent $t$-test, untuk menganalisis data independen pada kelompok kontrol dan perlakuan dan uji Paired t-test untuk menganalisis data berpasangan (pre and post test) pada kelompok perlakuan dan kelompok kontrol digunakan.

\section{HASIL PENELITIAN}

Suhu Tubuh Kelompok Perlakuan dan Kelompok Kontrol Pada Berbagai Waktu Pengukuran

Tabel 1. Suhu Tubuh Kelompok Perlakuan dan Kontrol Pada Pengukuran Menit ke 30 Setelah intervensi di Ruang Adenium RSUD Lawang

\begin{tabular}{|l|c|c|c|c|}
\hline Suhu tubuh & \multicolumn{3}{c|}{ Kelompok perlakuan } & \multicolumn{2}{c|}{ Kelompok Kontrol } \\
\hline \multicolumn{2}{|c|}{30 menit } & $\%$ & $\mathbf{N}$ & $\%$ \\
\hline & $\mathbf{N}$ & 0 & 0 & 0 \\
\hline Hipotermia & 0 & $7.70 \%$ & 0 & 0 \\
\hline Normal & 1 & $92.30 \%$ & 13 & $100 \%$ \\
\hline Febris & 12 & 0 & 0 & $\mathbf{1 0 0 \%}$ \\
\hline Hipertermia & 0 & $\mathbf{1 0 0 \%}$ & $\mathbf{1 3}$ & \\
\hline Total & $\mathbf{1 3}$ & & & \\
\hline
\end{tabular}

Berdasarkan tabel 1 diketahui bahwa suhu tubuh kelompok perlakuan pada menit ke 30 setelah itervensi sebagian besar pireksia sebanyak 12 anak (92,3\%), sedangkan pada kelompok kontrol semua responden dalam kondisi pireksia yaitu sebanyak 13 anak $(100 \%)$, 
Tabel 2 Suhu Tubuh Kelompok Perlakuan dan Kontrol Pada Pengukuran Menit ke 45 Setelah Intervensi di Ruang Adenium RSUD Lawang

\begin{tabular}{|l|c|c|c|c|}
\hline Suhu tubuh & \multicolumn{3}{c|}{ Kelompok perlakuan } & \multicolumn{2}{c|}{ Kelompok Kontrol } \\
\hline \multicolumn{2}{|c|}{$\mathbf{4 5}$ menit } & $\%$ & $\mathbf{N}$ & $\%$ \\
\hline Hipotermia & $\mathbf{N}$ & 0 & 0 & 0 \\
\hline Normal & 0 & $30.80 \%$ & 0 & 0 \\
\hline Febris & 9 & $69.20 \%$ & 13 & $100 \%$ \\
\hline Hipertermia & 0 & 0 & 0 & 0 \\
\hline Total & $\mathbf{1 3}$ & $\mathbf{1 0 0 \%}$ & $\mathbf{1 3}$ & $\mathbf{1 0 0 \%}$ \\
\hline
\end{tabular}

Berdasarkan tabel 2 diketahui bahwa suhu tubuh kelompok perlakuan pada menit ke 45 setelah intervensi sebagian besar pireksia sebanyak 9 anak $(69,2 \%)$, sedangkan pada kelompok kontrol semua responden masih dalam kondisi pireksia yaitu sebanyak 13 anak (100\%).

Tabel 3 Suhu Tubuh Kelompok Perlakuan dan Kontrol Pada Pengukuran Menit ke 60 Setelah Intervensi di Ruang Adenium RSUD Lawang

\begin{tabular}{|l|c|c|c|c|}
\hline Suhu tubuh & \multicolumn{2}{c|}{ Kelompok perlakuan } & \multicolumn{2}{c|}{ Kelompok Kontrol } \\
\hline \multicolumn{2}{|c|}{60 menit } & \%0 Menit \\
\hline & $\mathbf{N}$ & 0 & $\mathbf{N}$ & $\%$ \\
\hline Hipotermia & 0 & $30.80 \%$ & 2 & 0 \\
\hline Normal & 4 & $69.20 \%$ & 11 & $15.40 \%$ \\
\hline Febris & 9 & 0 & 0 & $84,6 \%$ \\
\hline Hipertermia & 0 & $\mathbf{1 0 0 \%}$ & $\mathbf{1 3}$ & $\mathbf{1 0 0 \%}$ \\
\hline Total & $\mathbf{1 3}$ & & & \\
\hline
\end{tabular}

Berdasarkan tabel 3 diketahui bahwa suhu tubuh kelompok perlakuan pada menit ke 60 setelah intervensi sebagian besar pireksia sebanyak 9 anak $(69,2 \%)$, sedangkan pada kelompok kontrol sebagian besar dalam kondisi pireksia yaitu sebanyak 11 anak $(84,6 \%)$, 
Tabel 4 Suhu Tubuh Kelompok Perlakuan dan Kontrol Pada Pengukuran Menit ke 90 Setelah Intervensi di Ruang Adenium RSUD Lawang

\begin{tabular}{|l|c|c|c|c|}
\hline Suhu tubuh & \multicolumn{2}{c|}{ Kelompok perlakuan } & \multicolumn{2}{c|}{ Kelompok Kontrol } \\
\hline \multicolumn{2}{|c|}{90 menit } & 90 Menit \\
\hline & $\mathbf{N}$ & 0 & $\mathbf{N}$ & $\%$ \\
\hline Hipotermia & 0 & $53.80 \%$ & 0 & 0 \\
\hline Normal & 7 & $46.20 \%$ & 4 & $30.80 \%$ \\
\hline Febris & 6 & 0 & 9 & $69.20 \%$ \\
\hline Hipertermia & 0 & $\mathbf{1 0 0 \%}$ & $\mathbf{1 3}$ & $\mathbf{1 0 0 \%}$ \\
\hline Total & $\mathbf{1 3}$ & & & \\
\hline
\end{tabular}

Berdasarkan tabel 4 diketahui bahwa suhu tubuh kelompok perlakuan pada menit ke 90 setelah intervensi sebagian besar normal sebanyak 7 anak $(53,8 \%)$, sedangkan pada kelompok kontrol sebagian besar masih dalam kondisi pireksia yaitu sebanyak 9 anak $(69,2 \%)$.

Tabel 5 Suhu Tubuh Kelompok Perlakuan dan Kontrol Pada Pengukuran Menit ke 120 Setelah Intervensi di Ruang Adenium RSUD Lawang

\begin{tabular}{|l|c|c|c|c|}
\hline Suhu tubuh & \multicolumn{2}{c|}{ Kelompok perlakuan } & \multicolumn{2}{c|}{ Kelompok Kontrol } \\
\hline \multicolumn{2}{|c|}{90 menit } & $\%$ & N Menit \\
\hline & $\mathbf{N}$ & 0 & 0 & $\%$ \\
\hline Hipotermia & 0 & $100 \%$ & 7 & $53.80 \%$ \\
\hline Normal & 13 & 0 & 6 & $46.20 \%$ \\
\hline Febris & 0 & 0 & 0 & 0 \\
\hline Hipertermia & 0 & $\mathbf{1 0 0 \%}$ & $\mathbf{1 3}$ & $\mathbf{1 0 0 \%}$ \\
\hline Total & $\mathbf{1 3}$ & & & \\
\hline
\end{tabular}

Berdasarkan tabel 5 diketahui bahwa suhu tubuh kelompok perlakuan pada menit ke 120 setelah intervensi semua responden dalam rentang normal yaitu 13 anak $(100 \%)$, sedangkan pada kelompok kontrol sebagian besar dalam kondisi normal yaitu sebanyak 7 anak $(53,8 \%)$ 
Rerata Suhu Tubuh Kelompok Perlakuan dan Kontrol pada Berbagai Waktu Pengukuran

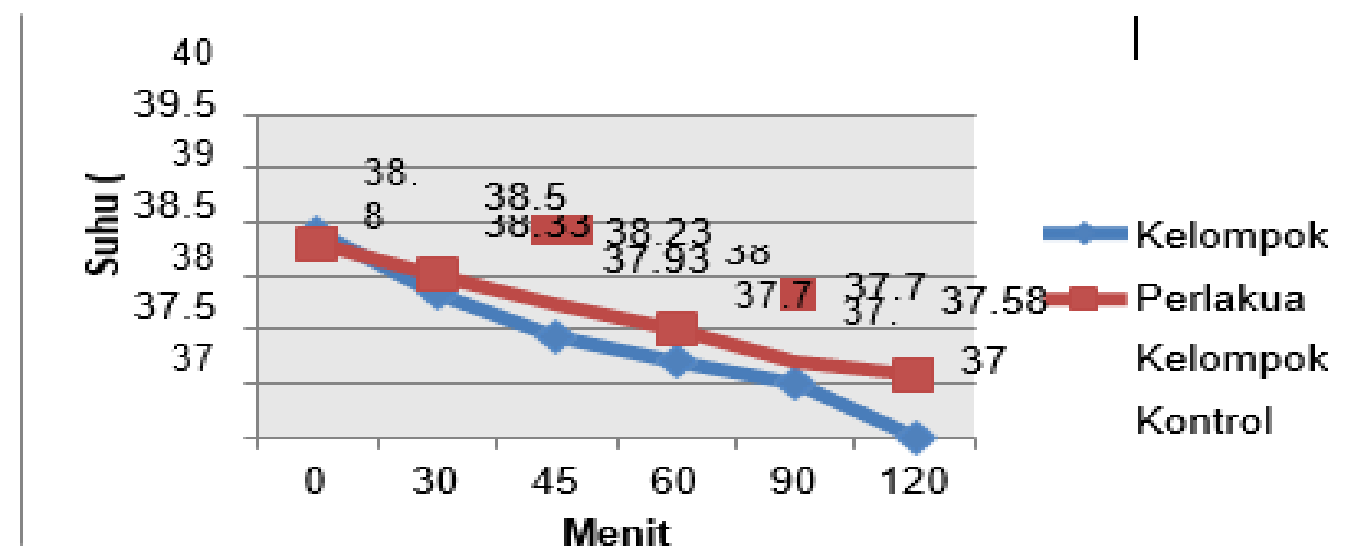

Berdasarkan tabel 6 sebelum dilakukan intervensi pada kelompok perlakuan, responden memiliki rerata suhu tubuh $38,9^{\circ} \mathrm{C}$ dan setelah intervensi selama 120 menit responden memiliki rerata suhu tubuh $37^{\circ} \mathrm{C}$, dengan demikian terjadi penurunan suhu sebesar $1,9^{\circ}$ C. Sedangkan pada kelompok kontrol rerata suhu sebelum diberikan intervensi adalah $38,8^{\circ} \mathrm{C}$ dan setelah diberikan intervensi selama 120 menit rerata suhu tubuh responden adalah $37,58^{\circ} \mathrm{C}$, terjadi penurunan suhu tubuh sebesar $1,22^{\circ} \mathrm{C}$.

1) Perbedaan Suhu Tubuh Sesudah Intervensi pada Kelompok Perlakuan dan Kontrol

Tabel 7 Hasil Uji Statistik Paired t-test Perbedaan Suhu Tubuh Sebelum dan Sesudah Intervensi pada Kelompok Perlakuan dan Kontrol di Ruang Adenium RSUD Lawang

\begin{tabular}{|c|c|c|c|c|c|}
\hline \multirow[t]{2}{*}{ Paired } & \multirow{2}{*}{\multicolumn{3}{|c|}{ Perbedaan suhu tubuh }} & \multicolumn{2}{|c|}{ Sig. $(2-$ tailed $)$} \\
\hline & & & & Perlakuan & Kontrol \\
\hline Pair 1 & $\begin{array}{l}\text { Sebelum dan } \\
\text { setelah } T S B\end{array}$ & 30 & menit & .000 & .004 \\
\hline Pair 2 & $\begin{array}{l}\text { Sebelum dan } \\
\text { setelah TSB }\end{array}$ & 45 & menit & .000 & .000 \\
\hline Pair 3 & $\begin{array}{l}\text { Sebelum dan } \\
\text { setelah } T S B\end{array}$ & 60 & menit & .000 & .000 \\
\hline Pair 4 & $\begin{array}{l}\text { Sebelum dan } \\
\text { setelah } T S B\end{array}$ & 90 & menit & .000 & .000 \\
\hline Pair 5 & $\begin{array}{l}\text { Sebelum dan } \\
\text { setelah } T S B\end{array}$ & 120 & menit & .000 & .000 \\
\hline
\end{tabular}

Berdasarkan tabel 7 pada kelompok perlakuan perbandingan antara sebelum diberikan intervensi dengan 30 menit, 45 menit, 60 menit, 90 menit, dan 120 menit setelah intervensi semua didapatkan $\mathrm{p}=0,000<0,05$ yang berarti $\mathrm{H} 0$ ditolak artinya ada perbedaan suhu tubuh antara sebelum diberikan intervensi TSB dengan 30 menit, 45 menit, 60 menit, 90 menit, dan 120 menit setelah pemberian intervensi TSB. Pada kelompok kontrol perbandingan suhu tubuh sebelum dengan 30 menit, 45 menit, 60 menit, 90 menit dan 120 menit setelah diberikan terapi 
standart sebagaimana mestinya didapatkan $\mathrm{p}<0,05$ masing - masing sebesar 0,004 dan 0,000 yang berarti H0 ditolak artinya ada perbedaan suhu tubuh antara sebelum dengan 30 menit, 45 menit, 60 menit, 90 menit dan 120 menit setelah diberikan terapi standart sebagaimana mestinya.

2) Perbedaan Suhu Tubuh antara Kelompok Perlakuan dan Kontrol

Tabel 8 Hasil Uji Statistik Independent Sample t-test Perbedaan Suhu Tubuh Antara Kelompok Perlakuan dan Kontrol di Ruang Adenium RSUD Lawang

\begin{tabular}{ccc}
\hline No. & $\begin{array}{c}\text { Perbedaan Suhu Tubuh Antara } \\
\text { Kelompok Perlakuan dan Kontrol }\end{array}$ & Sig. (2-tailed) \\
\hline 1. & 30 menit setelah intervensi & .313 \\
2. & 45 menit setelah intervensi & .043 \\
3. & 60 menit setelah intervensi & .060 \\
4. & 90 menit setelah intervensi & .170 \\
5. & 120 menit setelah intervensi & .000 \\
\hline
\end{tabular}

Berdasarkan tabel 8 diketahui bahwa perbedaan suhu tubuh kelompok perlakuan dan kelompok kontrol pada menit ke 30, 60, dan 90 setelah intervensi didapatkan semua nilai $\mathrm{p}>0,05$ masing masing $0,313,0,060$ dan 0,170 yang berarti $\mathrm{H} 0$ diterima artinya tidak ada perbedaan yang signifikan suhu tubuh antara kelompok perlakuan dan kontrol pada menit ke 30,60 dan 90 setelah intervensi, sedangkan pada menit ke 45, dan 120 setelah intervensi didapatkan nilai $\mathrm{p}$ semuanya $<0,05$ yang berarti H0 ditolak artinya ada perbedaan yang signifikan suhu tubuh antara kelompok perlakuan dan kontrol pada menit ke 45 dan 120 menit setelah intervensi

3) Perbandingan Suhu Tubuh Kelompok Perlakuan pada Berbagai Waktu Pengukuran

Tabel 9 Hasil Uji Statistik One Way Anova Perbandingan Suhu Tubuh Kelompok Perlakuan Pada Berbagai Waktu Pengukuran di Ruang Adenium RSUD Lawang

\begin{tabular}{llc}
\hline No. & Perbandingan Suhu Tubuh & $\begin{array}{c}\text { One Way Anova ( } \\
\text { Sig. 2-tailed) }\end{array}$ \\
\cline { 3 - 3 } & & Suhu Tubuh \\
1. & 30 menit setelah intervensi & .000 \\
2. & 45 menit setelah intervensi & \\
3. $\quad 60$ menit setelah intervensi & \\
4. 90 menit setelah intervensi & \\
5. 120 menit setelah intervensi & \\
\hline
\end{tabular}


Tabel 10 Uji Lanjut Bonferroni Games Howell Perbandingan Suhu Tubuh Kelompok Perlakuan Pada Berbagai Waktu Pengukuran di Ruang Adenium RSUD Lawang

\begin{tabular}{|c|c|c|}
\hline \multicolumn{3}{|c|}{ Comparisons Bonferroni Games - Howell Mean Difference } \\
\hline & & Suhu Tubuh \\
\hline \multirow[t]{4}{*}{$\begin{array}{l}30 \text { menit setelah } \\
\text { intervensi }\end{array}$} & $\begin{array}{l}45 \text { menit setelah } \\
\text { intervensi }\end{array}$ & .40692 \\
\hline & $\begin{array}{l}60 \text { menit setelah } \\
\text { intervensi }\end{array}$ & .59282 \\
\hline & $\begin{array}{l}90 \text { menit setelah } \\
\text { intervensi }\end{array}$ & .83077 \\
\hline & $\begin{array}{l}120 \text { menit setelah } \\
\text { intervensi }\end{array}$ & 1.19385 \\
\hline \multirow[t]{3}{*}{$\begin{array}{l}45 \text { menit setelah } \\
\text { intervensi }\end{array}$} & $\begin{array}{l}60 \text { menit setelah } \\
\text { intervensi }\end{array}$ & .18538 \\
\hline & $\begin{array}{l}90 \text { menit setelah } \\
\text { intervensi }\end{array}$ & .42385 \\
\hline & $\begin{array}{l}120 \text { menit setelah } \\
\text { intervensi }\end{array}$ & .78692 \\
\hline \multirow[t]{2}{*}{$\begin{array}{l}60 \text { menit setelah } \\
\text { intervensi }\end{array}$} & $\begin{array}{l}90 \text { menit setelah } \\
\text { intervensi }\end{array}$ & .23846 \\
\hline & $\begin{array}{l}120 \text { menit setelah } \\
\text { intervensi }\end{array}$ & .60154 \\
\hline $\begin{array}{l}90 \text { menit setelah } \\
\text { intervensi }\end{array}$ & $\begin{array}{l}120 \text { menit setelah } \\
\text { intervensi }\end{array}$ & .36308 \\
\hline
\end{tabular}

Berdasarkan tabel 10 berdasarkan analisis One Way Anova diketahui bahwa hasil uji perbandingan suhu tubuh pada menit ke 30, 45, 60, 90, dan 120 setelah intervensi Tepid Sponge Bath didapatkan nilai $\mathrm{p}=0,000<0,05$ yang berarti $\mathrm{H} 0$ ditolak artinya ada perbedaan yang sangat bermakna suhu tubuh pada menit ke 30, 45, 60, 90 dan 120 setelah intervensi Tepid Sponge bath.

\section{E. PEMBAHASAN}

\section{Suhu Tubuh Kelompok Perlakuan Sebelum dan Setelah Pemberian Intervensi}

Temuan penelitian ini didapatkan bahwa suhu tubuh kelompok perlakuan sebelum pemberian intervensi semua responden pada kondisi pireksia yaitu sebanyak 13 anak (100\%), pada menit ke 30 menit setelah intervensi sebagian besar pireksia sebanyak 12 anak (92,3\%), pada menit ke 45 dan 60 setelah intervensi sebagian pireksia masing masing sebanyak 9 anak $(69,2 \%)$, pada menit ke 90 setelah intervensi sebagian besar normal sebanyak 7 anak $(53,8 \%)$, dan pada menit ke 120 setelah intervensi semua responden pada rentang normal yaitu sebanyak 13 anak (100\%). Berdasarkan dari diagram 4.4 pada kelompok perlakuan sebelum diberikan intervensi, responden memiliki rerata suhu tubuh $38,9^{\circ} \mathrm{C}$ dan setelah diberikan intervensi selama 120 menit responden memiliki rerata suhu tubuh $37^{\circ} \mathrm{C}$, dengan demikian terjadi penurunan suhu sebesar $1,9^{0} \mathrm{C}$.

Hasil penelitian ini sejalan dengan penelitian Thomas, et al, (2009) yang dilakukan pada 150 klien anak yaitu setelah 120 menit pemberian tepid sponge bath dan obat antipiretik terdapat perubahan suhu $1,5^{\circ} \mathrm{C}$. Penurunan suhu tubuh pada penelitian ini sudah mencapai $1,9^{\circ} \mathrm{C}$ yang sesuai dengan teori Soedarmo, dkk. (2008) yaitu 10 $\mathrm{mg} / \mathrm{kg} \mathrm{BB}$ parasetamol dapat menurunkan $1,2-14^{\circ} \mathrm{C}$ dan tepid sponge bath dapat 
menurunkan suhu tubuh yang relatif tinggi (Aryani. dkk, 2009). Penelitian di India menunjukkan bahwa pemberian antipiretik yang disertai tindakan tepid sponge dengan air hangat dapat menurunkan suhu lebih cepat dibandingkan dengan pemberian antipiretik saja (Thomas, et al, 2009). Menurut penelitian Melasi (2013) terdapat kecenderungan bahwa pemberian antipiretik yang disertai tepid sponge bath mengalami penurunan suhu tubuh yang lebih besar dibandingkan dengan pemberian antipiretik saja.

Kompres adalah salah satu metode fisik untuk menurunkan suhu tubuh bila anak mengalami demam. Metode kompres yang lebih baik adalah kompres tepid sponge (Kolcaba, 2007:312). Penurunan suhu tubuh yang terjadi setelah diberikan antipiretik yang disertai tepid sponge bath dikarenakan obat antipiretik secara sentral menurunkan pusat pengaturan suhu di hipotalamus (Mubarak, Indrawati \& Susanto, 2015), sedangkan tepid sponge bath menggunakan efek evaporasi dalam menurunkan suhu tubuh (Vaughans, 2011) Dengan kompres hangat pada daerah yang mempunyai vaskular yang banyak,

maka akan memperluas daerah yang mengalami vasodilatasi. Vasodilatasi yang kuat pada kulit, akan memungkinkan percepatan perpindahan panas dari tubuh ke kulit, hingga delapan kali lipat lebih banyak (Anas Tamsuri, 2006).

Menurut peneliti hal tersebut menunjukkan bahwa penurunan suhu terjadi secara berkesinambungan, hal ini dikarenakan antipiretik yang dikolaborasikan dengan tepid sponge bath dapat membantu menurunkan suhu tubuh lebih tinggi karena obat antipiretik sendiri memiliki fungsi menurunkan suhu tubuh langsung pada pusat pengaturan suhu di hipotalamus, sedangkan tepid sponge bath memiliki efek evaporasi yang merubah cairan seperti keringat atau air di permukaan tubuh menjadi gas. Pada penelitian ini klien mendapatkan $10 \mathrm{mg} / \mathrm{kg}$ BB parasetamol dan tepid sponge bath selama 5-10 menit, dan menurunkan suhu sebanyak 1,9 $\mathrm{C}$ pada menit 120.

\section{Suhu Tubuh Kelompok Kontrol Sebelum dan Setelah Intervensi}

Berdasarkan hasil penelitian suhu tubuh kelompok kontrol sebelum intervensi dan pada menit ke 30 dan 45 setelah intervensi semua responden dalam kondisi pireksia yaitu sebanyak 13 anak (100\%), pada menit ke 60 setelah intervensi sebagian besar pireksia sebanyak 11 anak $(84.6 \%)$, pada menit ke 90 setelah intervensi sebagian besar masih dalam kondisi pireksia sebanyak 9 anak (69,2\%), dan pada menit ke 120 setelah intervensi sebagian besar dalam rentang normal sebanyak 7 anak (46,2\%). Berdasarkan dari diagram 4.4 dapat dilihat bahwa sebelum dilakukan intervensi rerata suhu adalah $38,8^{\circ} \mathrm{C}$ dan setelah diberikan intervensi selama 120 menit rerata suhu tubuh responden adalah $37,58^{\circ} \mathrm{C}$, terjadi penurunan suhu tubuh sebesar $1,22^{\circ} \mathrm{C}$.

Hasil penelitian ini sejalan dengan penelitian yang dilakukan oleh Thomas, dkk, (2009) yang dilakukan pada 150 klien anak yaitu setelah $120^{\circ} \mathrm{C}$ pemberian obat antipiretik terdapat perubahan suhu $1,3^{\circ} \mathrm{C}$, sedangkan penurunan suhu tubuh pada penelitian ini sudah mencapai $1,22^{\circ} \mathrm{C}$ yang sesuai dengan teori Soedarmo, dkk. (2008) yaitu $10 \mathrm{mg} / \mathrm{kg} \mathrm{BB}$ parasetamol dapat menurunkan $1,2-1,4^{0} \mathrm{C}$.

Penurunan suhu tubuh yang terjadi setelah diberikan obat antipiretik dikarenakan obat antipiretik menghambat siklooksigenase yaitu enzim yang berperan pada sintesis prostaglandin. Prostaglandin merupakan mediator penting untuk terjadinya demam. Kemudian obat antipiretik secara difusi dari plasma ke susunan syaraf pusat dan secara sentral menurunkan pusat pengaturan suhu di hipotalamus. Penurunan pusat suhu akan 
diikuti respon fisiologi yaitu penurunan produksi panas (Soedarmo, dkk. 2008)

Menurut peneliti hal tersebut menunjukkan bahwa penurunan suhu terjadi secara berkesinambungan, hal ini dikarenakan antipiretik yang diberikan sesuai dosis akan memberikan efek yang baik dalam penurunan suhu tubuh. Setelah pemberian dosis terapeutik parasetamol, penurunan demam terjadi setelah 30 menit. puncak dicapai sekitar 2 jam, dan demam akan rekurens 3-4 jam setelah pemberian. Kadar puncak plasma dicapai dalam waktu 30 menit. Makanan yang mengandung karbohidrat tinggi akan mengurangi absorpsi sehingga menghalangi penurunan demam. Dengan penurunan demam, aktivitas dan kesegaran anak akan membaik, sedangkan rasa riang dan nafsu makan belum kembali normal.

\section{Perbedaan Suhu Tubuh Antara Kelompok Perlakuan dan Kontrol}

Berdasarkan hasil penelitian menunjukkan bahwa penurunan suhu tubuh pada kelompok perlakuan selama 120 menit setelah intervensi Tepid Sponge Bath adalah sebesar $1,9^{0}$ C. Sedangkan pada kelompok kontrol penurunan suhu selama 120 menit setelah intervensi adalah sebesar $1,22^{\circ}$ C. Dan setelah dilakukan uji statistik Independent sample t-test didapatkan adanya perbedaan suhu tubuh kelompok perlakuan dan kelompok kontrol pada menit ke 45, dan 120 setelah intervensi didapatkan nilai $\mathrm{p}$ semuanya $<0,05$ yang berarti $\mathrm{H} 0$ ditolak artinya ada perbedaan yang signifikan suhu tubuh antara kelompok perlakuan dan kontrol pada menit ke 45 dan 120 menit setelah pemberian intervensi.

Hasil penelitian ini sejalan dengan penelitian di India menunjukkan bahwa pemberian antipiretik yang disertai tepid sponge bath dapat menurunkan suhu lebih cepat dibandingkan dengan pemberian antipiretik saja (Thomas, et al. 2009). Menurut penelitian Setiawati (2008) rata-rata penurunan suhu tubuh pada anak hipertermia yang mendapatkan terapi antipiretik ditambah tepid sponge sebesar $0.53^{\circ} \mathrm{C}$ dalam waktu 30 menit, sedangkan yang mendapat terapi tepid sponge saja rata-rata penurunan suhu tubuhnya sebesar $0,97^{\circ} \mathrm{C}$ dalam waktu 60 menit. Menurut penelitian Melasi (2013) terdapat kecenderungan bahwa pemberian antipiretik yang disertai tepid sponge bath mengalami penurunan suhu tubuh yang lebih besar dibandingkan dengan pemberian antipiretik saja.

Tepid sponge bath dengan air hangat merupakan tindakan pendinginan yang masih sering diperdebatkan. Totapally (2005) menjelaskan bahwa tepid sponge bath dengan air hangat jika dilakukan dengan benar akan sangat efektif menurunkan demam dengan cepat. Biasanya kompres akan menurunkan demam dalam tiga puluh sampai empat puluh lima menit (Shelov, 2005). Akan tetapi, efek tepid sponge bath dengan air hangat selain menurunkan suhu tubuh, juga menyebabkan vasokontriksi pada awal prosedur. Vasokontriksi ini menyebabkan anak merasa kedinginan bahkan sampai menggigil, terutama jika tidak dikombinasikan dengan antipiretik. Menurut peneliti penurunan suhu tubuh lebih cepat bila antipiretik diberikan bersama tepid sponge bath, hal ini dikarenakan antipiretik yang dikolaborasikan dengan tepid sponge bath dapat membantu menurunkan suhu tubuh lebih tinggi karena obat antipiretik sendiri memiliki fungsi menurunkan suhu tubuh langsung pada pusat pengaturan suhu di hipotalamus, sedangkan tepid sponge bath memiliki efek evaporasi yang merubah cairan seperti keringat atau air di permukaan tubuh menjadi gas. Tepid sponge bath sendiri akan menurunkan demam dalam tiga puluh sampai empat puluh lima menit setelah pemberiannya, sedangkan antipiretik dapat menurunkan suhu setelah 30 menit. puncak dicapai sekitar 2 jam, sehingga responden yang diberikan antipiretik disertai tepid 
sponge bath akan mengalami penurunan suhu tubuh yang signifikan pada menit 45 dan 120 menit setelah pemberian antipiretik disertai tepid sponge bath

\section{F. PENUTUP}

Berdasarkan hasil penelitian ini maka disimpulkan bahwa Ada efektifitas pemberian Tepid Sponge Bath terhadap penurunan suhu tubuh Anak yang mengalami kejang demam Ada perbedaan suhu tubuh sebelum dan sesudah pemberian Tepid Sponge Bath pada kelompok perlakuan. Ada perbedaan suhu tubuh sebelum dan sesudah pemberian antipiretik pada kelompok kontrol. Ada perbedaan suhu tubuh antara kelompok perlakuan dan kelompok kontrol pada menit ke 45 dan 120 setelah intervensi

\section{G. DAFTAR PUSTAKA}

Arikunto, S 2006, Prosedur Penelitian: Suatu Pendekatan Praktik. Edk VI, Rineka Cipta, Jakarta.

Asmadi 2008, Teknik Prosedural Keperawatan: Konsep Aplikasi Kebutuhan Dasar Klien, ctk 2, Salemba Medika, Jakarta.

Betz, CL \& Sowden, LA 2009, Buku Saku Keperawatan Pediatri, edk 5, EGC, Jakarta.

Dewanto, G, Suwono, WJ, Riyanto, B \& Turana, Y 2009, Panduan Praktis Diagnosis \& Tata Laksana Penyakit Saraf, EGC, Jakarta.

Irnawati 2010, Studi Komparatif Penurunan Suhu Tubuh Anak Demam Karena Infeksi Antara Penggunaan Obat Antipiretik, Plester Kompres Demam dan Obat Antipiretik Serta Tepid Sponge Bath dan Obat Antipiretik di Bangsal Ibnu Sina RS PKU Muhammadiyah Yogyakarta, UNISA Digital Library-Repository, diunduh 22 September 2016, <http://opac.unisayogya.ac.id/id/eprint/1754>

Isgianto, A 2009. Teknik Pengambilan Sampel Pada Penelitian Non Eksperimental, Mitra Cendikia, Jakarta.

Ismoedijanto 2000, 'Demam pada Anak', Sari Pediatri, vol. 2, no. 2, hh 103 - 108, diunduh 12 oktober 2016, <https://saripediatri.org/index.php/saripediatri/article/view/1037>

Kamtono, S 2014. Pengaruh Pendidikan Kesehatan Tentang Penanganan Kejang Demam Pada Balita Terhadap Self Efficacy Ibu di Desa Tempur Sari Tambak Boyo Mentingan Ngawi, diunduh 22

September 2016.

<http://stikeskusumahusada.ac.id/digilib/files/disk1/24/0 1184-1-artikel-s.pdf $>$

Koesrini, J 2015, 'Hubungan Pengetahuan Perawat Tentang Kejang Demam Dengan Penanganannya', Jurnal Kesehatan Hesti Wira Sakti, vol. 3, no. 3, hh. 24-30, $\begin{array}{llll}\text { diunduh } & 26 & \text { september }\end{array}$ http://www.adhamweb.com/jurnalpoltek/index.php?jour $\underline{\text { nal }=H W S \& p a g e}=$ article \&op $=$ view $\&$ path $\% 5 \mathrm{~B} \% 5 \mathrm{D}=93$ 
Krisanty, P, et.al 2011, Asuhan Keperawatan Gawat Darurat, CV.Trans Info Media, Jakarta.

Lalani, A \& Schneeweiss, S (ed) 2011, Kegawatdaruratan Pediatri, EGC, Jakarta.

Maling, B 2012, Pengaruh Kompres Tepid Sponge Hangat Terhadap Penurunan Suhu Tubuh Pada Anak Umur 1-10 Tahun Dengan Hipertermia, Karya ilmiah

S1 keperawatan, diunduh 22 Sepetember 2016,

$<$ http://pmb.stikestelogorejo.ac.id/e-

journal/index.php/ilmukeperawatan/article/view/85>

Melasi, P 2013, Pengaruh Tepid Sponge Bath Dengan Air Hangat Terhadap Penurunan Suhu Tubuh Pada Anak Usia Todler Dan Prasekolah Yang Mengalami Demam Di Ugd Rumah Sakit Ibu Dan Anak Family Jakarta Repository Universitas Esa Unggul, diunduh 1 September 2016, <http://digilib.esaunggul.ac.id>

Mubarak, WI, Indrawati, L \& Susanti, J 2015, Buku Ajar Ilmu Keperawatan Dasar Buku 1, Salemba Medika, Jakarta.

Ngastiyah 2005, Perawatan Anak Sakit, edk 2, EGC, Jakarta. Notoatmodjo, S 2012, Metodologi Penelitian Kesehatan. Rineka Cipta, Jakarta.

Nursalam 2011, Konsep dan Penerapan Metodologi Penelitian Ilmu Keperawatan, Salemba Medika, Jakarta.

Potter, AP \& Perry, GA 2006, Buku Ajar Fundamental Keperawatan, edk 4, vol. 2, EGC, Jakarta. Price, SA \& Wilson, LM 2005, Patofisiologi : Konsep Klinis Proses-Proses penyakit, vol. 2, EGC, Jakarta.

Purwoko, S 2005, Pertolongan Pertama Untuk Anak, Penerbit PT.Gramedia Pustaka Utama, Jakarta.

Putra, Mulyadi \& Ismanto 2014, 'Hubungan Pengetahuan Perawat Tentang Kejang Demam Dengan Penanganan Kejang Demam Pada Anak Di Instalasi Rawat Darurat Anak (Irda) Dan Ruang Perawatan Intensif (Rpi) Irina E Rsup Prof. Dr. R. D. Kandou Manado', Jurnal Kesehatan, vol. 2, no. 2, diunduh 26 september 2016 , \http://ejournal.unsrat.ac.id/index.php/jkp/article/view/5 $\underline{214>}$

Setiadi 2013, Konsep dan praktik penulisan Riset Keperawatan, Graha Ilmu, Yogyakarta.

Shelov, SP 2005, Panduan Lengkap Perawatan Untuk Bayi dan Balita, Penerbit Arcan, Jakarta.

Sodikin 2012, Prinsip Perawatan Demam pada Anak, Pustaka Pelajar,Yogyakarta.

Soedarmo, SS, Garna, H, Hadinegoro, SR \& Satari, HI 2008. Buku Ajar Infeksi \& Pediatric Tropis, edk 2, Badan Penerbit IDAI, Jakarta.

Sugiyono, 2012, Metode Penelitian Kuantitatif Kualitatif dan $R \& D$, Penerbit Alfabeta, Bandung.

Thomas, S, Vijaykumar, C, Naik, R, \& Moses, Pd 2009, 'Comparative Effectiveness of Tepid Sponging and Antipyretic Drug Versus Only Antipyretic Drug in the Management of Fever Among Children', Indian Pediatrics, vol. 46, diunduh 20 September 2016, <http://web.a.ebscohost.com> 
Unit Kerja Koordinasi Neurologi Ikatan Dokter Anak Indonesia, 2006, Konsensus

Penatalaksanaan Kejang Demam, diunduh 6 oktober 2016, <http://www.idai.or.id/wpcontent/uploads/2013/02/Kejang-Demam-Neurology- 2012.pdf>

Vaughans, BW 2011, Keperawatan Dasar, edk 1, Rapha Publishing, Yogyakarta.

Wasis, 2008, Pedoman Riset Keperawatan Untuk Profesi Perawat, Penerbit Buku Kedokteran EGC, Jakarta. http://image.slidesharecdn.com/duj0eq4yqts74417csjwphpapp01/95/penatalaksanaan-kejang-demam638.jpg?cb=1413616130) diunduh 26 oktober wib. $\underline{140530041129-}$ konsensus-idai-92016 pukul 20.30 